\title{
Pengaruh Customer Relationship Management Terhadap Loyalty Intention Dengan Word Of Mouth Sebagai Mediasi
}

\author{
Raden Bagus Faizal Irany Sidharta \\ Program Studi Manajemen Universitas Bumigora \\ Email : ronyfaiza193@gmail.com
}

\begin{abstract}
Abstrak
Penelitian ini bertujuan untuk mengetahui dan menganalisis signifikansi pengaruh: 1) customer relationship management terhadap Loyalty Intentionpada travel agent di Mataram. 2) Word of Mouthterhadap Loyalty Intentionpada travel agent di Mataram. 3) customer relationship management terhadap Word of Mouthpada travel agent di Mataram. 4) Customer relationship management terhadap loyalty intentionmelalui Word of Mouth Pada Travel Agent Di Mataram. Jenis penelitian ini adalah penelitian kausalitas dengan pendekatan kuantitatif. Jumlah responden yang digunakan dalam penelitian ini adalah 100 orang pelanggan yang berkunjung ke Pulau Lombok dengan rentang usia 15-65 tahun dan pernah menggunakan travel agent di Mataram. Uji kuesioner menggunakan uji validitas, uji reliabilitas dan uji Asumsi klasik. Analisis data menggunakan analisis path dengan program SPSS 16.00. Berdasarkan hasil penelitian dan pembahasan dapat disimpulkan sebagai berikut: 1) terdapat pengaruh langsung, positif dan signifikan antara variabel customer relationship management terhadap Loyalty Intentionpada travel agent di Mataram. 2) terdapat pengaruh langsung, positif dan signifikan antara variabel Word of Mouthterhadap Loyalty Intentionpada travel agent di Mataram. 3) terdapat pengaruh langsung, positif dan signifikan antara variabel customer relationship management terhadap Word of Mouthpada travel agent di Mataram. 4) terdapat pengaruh langsung, positif dan signifikan antara variabel Customer relationship management terhadap loyalty intentionmelalui Word of Mouth Pada Travel Agent Di Mataram.
\end{abstract}

Kata kunci : customer relationship management, loyalty intention, word of mouth 


\section{Pendahuluan}

Langkah yang harus ditempuh dalam mengantisipasi adanya persaingan yang ketat mengharuskan setiap industri melakukan berbagai strategi dengan bentuk dan cara yang berkualitas dalam segala aspek. Strategi pemasaran diperlukan untuk mendapatkan dan meningkatkanmarket share bagi perusahaan. Selain itu, dalam kegiatan pemasaran memiliki tujuan yaitu memproduksi barang yang akan dikonsumsi oleh pembeli. Berkaitan dengan hal tersebut, dalam mencapai berbagai tujuan perusahaan penting untuk mengetahui,memahamidan mempelajari perilaku konsumen yaitu salah satunya adalah faktor-faktor yang dapat mempengaruhi loyalty intention yang terus mengalami perubahan yang dinamis dari waktu ke waktu.

Menurut McDougall dan Levesque (2001) loyalty intention atau niat untuk loyal bukan merupakan loyalitas tentang sikap maupun loyalitas keperilakuan, tetapi niat untuk loyal tersebut didefinisikan sebagai kemungkinan yang subjektif bahwa seorang konsumen akan berperilaku loyal setelah melakukan pembelian ulang, merekomendasikan kepada orang lain, atau melakukan positif word of mouth. Menurut Parasuraman et al dalam Akbar dan parvez (2009:27), loyalitas konsumen tidak muncul begitu saja pada seseorang, tetapi tercipta melalui beberapa tahap yang diawali dengan munculnya suatu keinginan atau niat untuk loyal (loyalty intention). Loyalitas konsumen tersebut merupakan kerangka berfikir dari konsumen yang memegang sikap suka terhadap suatu perusahaan dan berkomitmen untuk membeli lagi produk atau jasa perusahaan (Neupane, 2015)

Konsumen lebih mempercayai Word Of Mouth (WOM) daripada media iklan, hal ini dikarenakan masyarakat sudah lama menggunakan model Word Of Mouth (WOM) yang prinsipnya agar berita, pemberitahuan, undangan dan informasi lainnya disampaikan secara meluas dari mulut ke mulut secara lisan.Selain itu alasan konsumen lebih mempercayai komunikasi Word Of Mouth (WOM) adalah informasi yang didapatkan berasal dari orang-orang yang terdekat dianggap dapat mempengaruhi presepsi konsumen tentang keunggulan dari suatu produk. Menurut Silverman (2001), rekomendasi pelanggan merupakan alat promosi dan penjualan yang sangat efektif dalam mempengaruhi calon pelanggan. Konsumen yang memiliki pengalaman unik tentang produk, jasa, dan merek dari perusahaan tertentu cenderung akan membicarakannya kepada orang lain (Hasan, 2010).Hal tersebut sesuai dengan hasip penelitian yang dilakukan oleh Wangenheim (2005) bahwa Word Of Mouth(WOM) dapat mempengaruhi loyalty intention dari pelanggan dan diperkuat oleh hasil Penelitian yang dilakukan oleh Trusov, Bucklin \& Pauwels (2008) yang menemukan bahwaword of mouth dapat mempengaruhi loyalty intention dari konsumen. Namun sebaliknya,penelitian yang dilakukan olehDoong (2008) menemukan word of mouth tidak berpengaruh terhadap loyalty intention pada pelanggan.

Penelitian yang dilakukan oleh Philips et al (2013) menemukan bahwa word of mouth memiliki pengaruh yang besar terhadap wisatawan berkunjung ke suatu destinasi wisata.Pulau Lombok sebagai salah satu daerah destinasi wisataterus menunjukkan peningkatan angka kunjungan wisatawan baik wisatawan domestik maupun wisatawan luar negeri. Hal ini berimbas pada pesatnya berbagai usaha jasa yang berkaitan langsung dengan dunia pariwisata, salah satu perusahaan jasa yang bergerak dalam biro perjalanan atau lebih dikenal dengan sebutan Travel Agent. 
Dari sekian banyak travel agent, terdapat 5 travel agent yang telah beroperasi di Kota Mataram. Berdasarkan wawancara awal pada 5 travel agent tersebut, kelima travel agent di KotaMataram tersebut masih sangat jarang membangun hubungan yang konstruktif dengan pelanggan. Hal ini menyebabkan kurangnya ikatan pelanggan dengan travel yang kemungkinan dapat menyebabkan pelanggan tidak menggunakan travl agent itu kembali.Hal ini-pun terlihat dari data jumlahpelanggan dalam kurun waktu 5 tahun terakhir pada5travel agentyang ada di Mataram dari tahun 2012 hingga 2016.

Penelitian yang dilakukan oleh (Adnin, Lubis, \& Widayanto, 2013) menemukan bahwa Customer Relationship Management berpengaruh positif dan signifikan terhadap niat untuk loyal pelanggan PT.Nasmoco Pemuda Semarang.Penelitian yang dilakukan oleh (Oktariana, Fauzi, \& Kumadji, 2017) dengan judul Faktor-Faktor Customer Relationship Management Dalam Mewujudkan Kepuasan Anggota dan Dampaknya Terhadap Loyalitas Anggota, penelitian ini termasuk explanatory research dengan sampel 68 orang dari 677 populasi dan hasil penelitian ini adalah tidak ada pengaruh antara CRM dengan loyalitas pelanggan. Penelitian yang dilakukan oleh (Yuristika, Faridia, \& Dewi, 2015) dengan judul Pengaruh Customer Relationship Management (CRM) Dan Kualitas Layanan Terhadap Pembelian Ulang Melalui Word Of Mouth Sebagai Variabel Mediasi dengan menggunakan multi stage random sampling dan jumlah responden 100 orang, menggunakan teknik analisa jalur ditemukan bahwa Customer Relationship Managementberpengaruh terhadap word of mouth Penelitian yang dilakukan oleh (Rika, 2017) dengan judul Model Loyalitas Pelanggan Berbasis Customer Relationship Management dengan menggunakan purposive sampling dan menggunakan metode analisa jalur, penelitian ini menemukan bahwa terdapat pengaruh positif dan signifikan antara CRM terhadap loyalitas pelanggan. Penelitian yang dilakukan oleh Lubis (2016)dengan judul Analisis Pengaruh Brand Equity, Kualitas Pelayanan Dan Word of Mouth Positif Terhadap Loyalitas Konsumen Dengan Kepuasan Konsumen Sebagai Variabel Intervening, dengan menggunakan teknik sampling random atau acak, dimana semua individu di dalam populasi memeiliki kesempatan yang sama untuk mewakili dalam penelitian, lalu pengumpulan data menggunakan kuesioner dan data dianalisis dengan program SPSS 20.0 memiliki hasil bahwa dari analisis regresi linier berganda menunjukkan bahwa brand equity berpengaruh positif terhadap kepuasan konsumen, kualitas pelayanan berpengaruh terhadap kepuasan konsumen, dan word of mouth positif memiliki pengaruh yang positif dan signifikan terhadap loyalitas konsumen.

Penelitian yang di lakukan oleh Topcu dan Daygun (2015)dengan judul penelitian The Impacts of Customer Loyalty on Negative Word of Mouth Communication and Repurchase Intention, pengumpulan data dilakukan dengan survey pada nasabah bank di Turki dengan menggunakan multiple regression model memiliki hasil bahwa word of mouth yang negatif akan mempengaruhi atau menurunkan niat untuk loyal dan menurunkan perilaku pembelian ulang terhadap suatu produk.Penelitian yang dilakukan oleh Kim dan Han (2008) dengan judul Determinants of Restaurant Customers Loyalty Intentions: A Mediating Effect of Relationship Quality, data di analisis dengan menggunakan regresi berganda dan data dikumpulkan dengan caraonline survey memiliki hasil bahwa relationship quality berpengaruh sebagai mediasi antara perceived value dan loyalty intentions.Penelitian yang dilakukan oleh Riduan (2010)dengan judul Pengaruh Word of 
Mouth Communication terhadap Loyalitas Pelanggan Pada Jasa Travel Muara Wisata Trayek Lampung-Jakarta dengan menggunakan analisis regresi linier berganda dan dengan bantuan program SPSS 13 maka ditemukan bahwa WOM communication positif akan berpengaruh atau akan meningkatkan loyalitas dari pelanggan pada jasa Travel Muara Wisata Trayek Lampung-Jakarta dan WOM communication negatif akan berpengaruh atau akan menurunkan loyalitas dari pelanggan pada jasa Travel Muara Wisata Trayek Lampung-Jakarta.

Penelitian yang dilakukan oleh Alias dan Roslin (2014)dengan judul penelitian The Mediating Role of Experiental Values on Servicescape Strategies and Loyalty Intention of Department Store Customers in Malaysia, jenis penelitian merupakan penelitian explanatory dan menggunakan kuesioner sebagai alat pengumpulan data maka hasil yang didapatkan dari penelitian ini adalah servicescape berpengaruh terhadap loyalty intention dan experiental values berperan sebagai variabel moderasi.Penelitian yang dilakukan oleh Carolina (2013) dengan judul penelitian pengaruh word of mouth terhadaployalitas pelanggan pada salon khairunnisa di Bandung memiliki hasil bahwa word of mouth berpengaruh tidak signifikan terhadap loyalitas pelanggan salon khairunnisa di Bandung.Penelitian yang dilakukan oleh Yunita dan Haryanto (2012)dengan judul pengaruh word of mouth terhadap loyalitas konsumen es krim menemukan hasil bahwa word of mouth memiliki pengaruh signifikan terhadap loyalitas konsumen.Penelitian yang dilakukan oleh (Semuel, 2012) dengan judulCustomer Relationship Marketing Pengaruhnya Terhadap Kepercayaan dan Loyalitas Perbankan Nasional, sebanyak 165 responden dan data dianalisis dengan Generalized Structures Component Analysis. Hasil penelitian menunjukkan bahwa CRM tidak berpengaruh terhadap loyalitas pelanggan.

Berdasarkan beberapa penelitian terdahulu di atas, menunjukan bahwa customer relationship managementberpengaruh signifikan dan positifterhadap loyalty intention dan word of mouthberpengaruh signifikan dan positifterhadaployalty intention, akan tetapi terdapat juga hasil yang berbeda. Oleh karena itu peneliti tertarik mengembangkan penelitian yang berhubungan dengan customer relationship management,word of mouthdan loyalty intention. Dengan adanya fenomena seperti yang dikemukakan diatas dan masih adanya perbedaan hasil penelitian atau adanyaresearch gap(celah penelitian), penulis tertarik untuk melakukan penelitian yang berkaitan dengancustomer relationship management, word of mouth dan loyalty intention.

\section{Tujuan Penelitian}

Adapun tujuan dalam penelitian ini yaitu:

1. Untuk membuktikan dan menganalisis signifikansi pengaruh dariCustomer relationship management terhadap loyalty intention pada Travel Agent di Mataram

2. Untuk membuktikan dan menganalisis signifikansi pengaruh dariWord of Mouth berpengaruh terhadap loyalty intention padaTravel Agent di Mataram

3. Untuk membuktikan dan menganalisis signifikansi pengaruh dariCustomer relationship managementterhadap word of mouth padaTravel Agent di Mataram 


\section{Kajian Kepustakaan dan Pengembangan Hipotesis}

\subsection{Kajian Kepustakaan}

Customer relationship management (CRM)adalah satu proses dalam mendapatkan, mempertahankan dan meningkatkan hubungan pelanggan yang menguntungkan dengan tujuan untuk menciptakan nilai pelanggan, sehingga pelanggan puas dan memaksimalkan keuntungan bagi perusahaan dalam rangka memperoleh keunggulan bersaing, memperhatikan mutu produk agar dapat memberikan kepuasan yang prima bagi pelanggan (Alma, 2010)..

Dari seluruh media promosi baik itu Above The Line maupun Below The Line, Word Of Mouth(WOM) merupakan aktivitas promosi yang tingkat pengendaliannya oleh pemasar sangat rendah tetapi memberikan dampak yang sangat luar biasa terhadap produk atau merek perusahaan, (Solomon, 2007). Sweeney et al (2006) mengemukakan bahwa pada intinya, Word Of Mouth(WOM) adalah proses pengaruh personal antara pengirim dan penerima dalam komunikasi interpersonal yang mana dapat mengubah perilaku maupun pikiran si penerima.

Priharmoko (2003) mengemukakan tiga alasan mengapa Word of mouth (WOM) menjadi sangat penting bagi perusahaan, yakni :a) Noise; Konsumen mendapatkan banyak informasi tentang produk, dan melalui informasi dari teman, mereka mendapatkan filter untuk menyaring info tersebut. b) Skepticism; Konsumen tidak mudah percaya terhadap informasi yang diberikan oleh produsen dan skeptic dalam menanggapinya, c) Connectivity; Antara satu konsumen dengan konsumen lainnya saling berhubungan satu sama lain dalam suatu jaringan yang invisible dan terkoneksi.

Menurut Godes \& Mayzlin (2004 : 545-560) dalam Paulus, Bessie and Kasim, (2015) terdapat dua elemen untuk mengukur WOM, yaitu :

1. Volume;

Pada elemen ini akan diukur seberapa banyak WOM yang ada. Selain itu dapat pula dianalogikan sebagai frekuensi yakni seberapa sering orang membicarakan atau merekomendasikan. Semakin banyak percakapan yang terjadi, tentunya akan semakin banyak orang yang mengetahui tentang hal tersebut.

Variabel volume diukur menggunakan empat indicator yaitu: a) Sering mendengar, b) Sering melakukan diskusi dengan teman atau keluarga tentang keunggulan produk atau jasa tertentu, c) Sering mendapat rekomendasi dari teman atau keluarga, d) Sering memberikan rekomendasi kepada teman atau keluarga untuk menggunakan produk atau jasa tertentu (Godes \& Mayzlin, 2004 : 545-560).

2. Dispersion;

Elemen ini mendefinisikan sebagai tingkat dimana percakapan mengenai produk mengambil tempat di dalam komunikasi yang luas. Hal ini dapat dianalogikan sebagai jangkauan, yakni berapa banyak orang berbeda yang membicarakan.

Variabel dispersion diukur menggunakan empat indikatoryaitu: a) Pernah b) Mendengar dari kenalan, c) Mendengar dari orang yang pernah berkunjung, d) Mendengar dari orang yang belum pernah berkunjung (Godes \& Mayzlin, 2004 : 545560). 
Menurut Swastha (1999:144) loyalitas dipandang sebagai hubungan yang erat antara sikap yang relatik dengan perilaku pembelian ulang.Fishbein dan Ajzen (1975:288), mendefinisikan bahwa niat berperilaku itu sebagai kemungkinan yang subjektif dari seseorang untuk melakukan tindakan tertentu. Selanjutnya Fishbein dan Ajzen (1975:292) mengatakan bahwa niat terkait dengan empat unsur yang berbeda yaitu perilaku (behavior), objek (target) yang menjadi sasaran, situasi (situation) perilaku dijalankan dan waktu tersebut perilaku dimunculkan. Mengacu pada pendapat Fishbein dan Ajzen (1975) tersebut, maka kesimpulan operasional dari variabel loyalitas sebagai niat untuk loyal seperti yang digunakan oleh Mc.Dougall dan Levesque (2001), dimana niat untuk loyal bukan merupakan loyalitas tentang kesikapan maupun loyalitas keperilakuan, tetapi niat untuk loyal tersebut didefinisikan sebagai kemungkinan yang subjektif bahwa seorang konsumen akan berperilaku loyal (melakukan pembelian ulang, merekomendasikan kepada orang lain, atau melakukan positif word of mouth setelah merasakan manfaat dari suatu produk atau jasa yang sudah dikonsumsi).

\subsection{Hipotesis}

Berdasarkan latar belakang, tujuan penelitian dan kajian kepustakan, maka hipotesis penelitian ini adalah sebagai berikut.

\subsubsection{Pengaruh Customer Relationship Managementterhadap Loyalty Intention}

Customer Relationship Management (CRM) merupakan suatu strategi perusahaan yang dapat digunakan untuk memanjakan pelanggan agar tidak berpaling ke perusahaan pesaing (Rika, 2017). Penerapan program CRM diharapkan mampu membuat pelanggan menjadi setia kepada perusahaan sehingga hubungan yang terjadi tidak hanya hubungan antara penjual dan pembeli, tetapi lebih mengarah kepada hubungan mitra.Perusahaan lebih dapat memahami apa yang diinginakn dan dibutuhkan oleh pelanggan sehingga pelanggan akan tetap menggunakan produk dan jasa yang ditawarkan oleh perusahaan (Rika, 2017).

Strategi CRM yang baik dapat meningkatkan penjualan dengan memperbaiki hubungan dengan pelanggan sehingga pelanggan menjadi loyal dengan perusahaan (Oktariana, Fauzi, \& Kumadji, 2017).Penelitian yang dilakukan oleh penelitian yang dilakukan oleh (Adnin, Lubis, \& Widayanto, 2013) menemukan bahwa Customer Relationship Management berpengaruh positif dan signifikan terhadap niat untuk loyal pelanggan PT.Nasmoco Pemuda Semarang.

Hipotesis 1 :Customer relationship management berpengaruh signifikanterhadap loyalty intentionPada Travel Agent Di Mataram.

\subsubsection{PengaruhWord Of Mouth terhadap Loyalty Intention}

Menurut (Solomon, 2007) dari seluruh media promosi baik itu Above The Line maupun Below The Line, Word of mouth(WOM) merupakan aktivitas promosi yang tingkat pengendaliannya oleh pemasar sangat rendah tetapi memberikan dampak yang sangat luar biasa terhadap produk atau merek perusahaan. Menurut Hasan (2010) Word Of Mouth(WOM)merupakan cara dalam mempromosikan suatu produkdari "orang ke orang" yang puas untuk meningkatkan kesadaran produk dan menghasilkan tingkat penjualan tertentu Komunikasi dari mulut ke mulut 
menyebar melalui jaringan bisnis, sosial dan masyarakat yang dianggap sangat berpengaruh, efeisien dari segi biaya, dan cara cepat untuk menyebarluaskan informasi produk (Martini, 2013).Dalam Word of mouth(WOM), konsumenlah yang memutuskan tentang sesuatu yang sangat berharga untuk dibicarakan. Konsumen yang memiliki pengalaman unik tentang produk, jasa, dan merek dari perusahaan tertentu cenderung akan membicarakannya kepada orang lain (Hasan, 2010).

Hipotesis 2: Word of Mouth berpengaruh signifikanterhadap loyalty intentionPada Travel Agent Di Mataram.

\subsubsection{PengaruhCustomer Relationship Management terhadap Word of Mouth}

Menurut WOMMA (Word Of Mouth Marketing Association), Word Of Mouth(WOM) adalah suatu aktivitas di mana konsumen memberikan informasi mengenai suatu merek atau produk kepada konsumen lain. Sedangkan Word of Mouth Marketing menurut Hasan (2010) merupakan bagian dari strategi promosi dalam kegiatan pemasaran yang menggunakan "orang ke orang" yang puas untuk meningkatkan kesadaran produk dan menghasilkan tingkat penjualan tertentu.Untuk membentuk word of mouth perusahaan perlu membangun hubungan yang lebih dekat dengan konsumennya melalui customer relationship management

Hipotesis 3: Customer relationship managementberpengaruh signifikan terhadap Word of Mouth Pada Travel Agent Di Mataram.

\subsubsection{PengaruhCustomer relationship management terhadap Loyalty Intention melaluiWord of Mouth}

Perusahaan perlu melakukan customer relationship managementagar mampu mempertahankan dan menjaga hubungan baik dengan konsumennya atau pelanggannya, hal ini penting karena ketika hubungan baik antara perusahaan dengan pelanggan sudah terjalin maka pelanggan akan merasa nyaman dan memiliki intensi untuk loyal kepada perusahaan (Davis,2002). Di sisi yang lain, word of mouth akan mampu mempengaruhi perilaku dari para pembeli dan akan mengevaluasi setiap pembelian akan suatu produk yang menentukan loyalitas dari pelanggan tersebut, konsumen akan dengan mudah terpengaruh ketika sudah ada word of mouth baik itu yang positif maupun negatif terhadap suatu jasa (Gremmer,1994).

Hipotesis 4: Customer relationship managementberpengaruh signifikan terhadap loyalty intentionmelalui Word of Mouth Pada Travel Agent Di Mataram.

\section{Metode Penelitian}

Penelitian ini menggunakan jenis penelitian kausalitas dengan sampel yaitu 100 orang dari populasi pelanggan yang berkunjung ke Pulau Lombok yang didapatkan melalui purposive sampling. Data akan dikumpulkan menggunakan kuesioner yang mencatat respon dari sampel. 


\section{Hasil dan Pembahasan}

\begin{tabular}{|l|l|l|l|l|l|}
\hline Hipotesis & $\begin{array}{l}\text { Hubungan } \\
\text { Antar Variabel }\end{array}$ & $\begin{array}{l}\text { Koefisien } \\
\text { Jalur }\end{array}$ & $\begin{array}{l}\text { T- } \\
\text { Statistik }\end{array}$ & \multicolumn{2}{|l|}{ Kesimpulan } \\
\hline $\mathbf{1}$ & $\begin{array}{l}\text { Customer Relationship } \\
\text { Management } \rightarrow \text { Word } \\
\text { of Mouth }\end{array}$ & 0,371 & 3,692 & Signifikan & Terdukung \\
\hline Hipotesis2 & $\begin{array}{l}\text { Customer Relationship } \\
\text { Management } \rightarrow \text { Loyalty } \\
\text { Intention }\end{array}$ & 0,366 & 1,826 & Signifikan & Terdukung \\
\hline Hipotesis3 & $\begin{array}{l}\text { Word of } \\
\text { Mouth } \rightarrow \text { Loyalty } \\
\text { Intention }\end{array}$ & 0,236 & 1,876 & Signifikan & Terdukung \\
\hline
\end{tabular}

Tabel diatas menunjukkan bahwa dari 3 hubungan antar variabel yang diajukan 3 hubungan antar variabel lainnya signifikan.

\begin{tabular}{|l|c|c|c|}
\hline & Pengaruh Variabel & $\begin{array}{c}\text { Formula } \\
\text { Perhitungan }\end{array}$ & Hasil \\
\hline & Rangkuman Pengaruh Langsung (Direct Effect) & \\
\hline Hipotesis 1 & $\begin{array}{c}\text { Customer relationship management } \\
(\mathrm{X}) \rightarrow \text { Loyalty Intention }(\mathrm{Y})\end{array}$ & - & 0,371 \\
\hline Hipotesis 2 & $\begin{array}{c}\text { Customer Relationship Management } \\
(\mathrm{X}) \rightarrow \text { Word of Mouth (Z) }\end{array}$ & - & 0,366 \\
\hline Hipotesis 3 & $\begin{array}{c}\text { Word of Mouth (Z) } \rightarrow \text { Loyalty } \\
\text { Intention (Y) }\end{array}$ & - & 0,236 \\
& $\begin{array}{c}\text { Rangkuman Pengaruh Tidak Langsung (Indirect } \\
\text { Effect) }\end{array}$ & 0,086 \\
& $\begin{array}{c}\text { Customer Relationship Management } \\
(\mathrm{X} \rightarrow \text { Word of Mouth }(\mathrm{Z}) \rightarrow \text { Loyalty } \\
\text { Intention }(\mathrm{Y})\end{array}$ & $\begin{array}{c}(0,366 \times \\
0,236)\end{array}$ \\
\hline
\end{tabular}

Dengan demikian diketahui bahwa variabel customer relationship management dengan mediasi word of mouthdapat mempengaruhi loyalty intetnion wisatawan yang berkunjung ke pulau Lombok dan menggunakan travel agent di Mataram dengan nilai koefisien jalur sebesar 0,086.

Dari perhitungan tersebut, memberi arti bahwaterdapat pengaruh tidak langsung antara variabel custromer relationship management dengan loyalty intentionmelalui word of mouth dengan nilai koefisien jalur sebesar 0,086. Perbandingan pengaruh tidak langsung customer relationship management dengan loyalty intentionmelalui word of mouth dengan pengaruh langsungnya antara customer relationship managementterhadap loyalt intentiondiperoleh hasil 0,086<0,371 sehingga bisa dinyatakan bahwa word of mouth berfungsi sebagai mediasi parsial (partial mediation) dalam pengaruh customer relationship managementterhadap loyalty intentionpada wisatawan yang berkunjung ke pulau Lombok dan menggunakan travel agent di Mataram. Artinya customer relationship management mampu mempengaruhi 
loyalty intetnionsecara signifikan baik melalui word of mouth ataupun tanpa word of mouth.

Penelitian ini bertujuan untuk mengetahui pengaruh customer relationship management terhadaployalty intentiondenganmediasiword of mouthpadatravel agent di Mataram.Pengujian ditunjukkan melalui hipotesis yang ada sehingga dapat mengetahui bagaimana pengaruh masing-masing variabel terhadap variabel lainnya.

\subsection{Pengaruh Customer Relationship Management Terhadap Loyalty Intention}

Hasil analisis data menunjukkan bahwa customer relationship managementberpengaruh positif dan signifikan terhadaployalty intetnion.Sehingga hipotesis 1 yang menyatakan "customer relationship management berpengaruh positif signifikan terhadap loyalty intention" di terima.

Manajemen hubungan pelanggan atau customer relationship management (CRM)) merupakan suatu kegiatan untuk mengidentifikasi, menarik dan mempertahankan pelanggan yang paling bernilai bagi perusahaan. Manajemen hubungan pelanggan dapat membantu perusahaan meningkatkan laba dengan menerapkan strategi yang berfokus pada pelanggan dan berkonsentrasi pada apa yang pelanggan nilai bukan pada apa yang perusahaan jual. Tujuan akhir dari customer relationship management adalah untuk mendapatkan loyalty intention dan akhirnya menjadi pelanggan yang setia (Semuel,2012). Menurut Alma (2010:296) customer relationship management bertujuan untuk memaksimalkan keuntungan perusahaan dengan berfokus dan berorientasi pada pelanggan untuk memperoleh keunggulan bersaing atau competitive advantage. Usaha yang dilakukan oleh perusahaan dalam menjaga hubungan dengan pelanggannya adalah usaha untuk terus mempertahankan pelanggan hingga tercapai keberlanjutan dari perusahaan itu sendiri.

Agar perusahaan mampu bertahan, perusahaan harus menganggap pelanggan merupakan aset yang sangat penting.Maka, hubungan atau relationship antara perusahaan dan pelanggan sangat penting demi keberlangsungan perusahaan.Customer relationship management perlu diterapkan di perusahaan, CRM merupakan suatu pendekatan yang berbasis hubungan untuk berbisnis. Hubungan dalam berbisnis disini adalah pemahaman tentang apa yang dibutuhkan dan diinginkan pelanggan serta memandang pelanggan sebagai aset jangka panjang yang akan memberikan pemasukan terus menerus selama kebutuhan pelanggan terpenuhi. Customer relationship management merupakan modal perusahaan untuk mempertahankan dan meningkatkan loyalitas pelanggan dalam meraih keuntungan jangka panjang (Oktariana et al, 2017)

Loyalty intention atau niat untuk loyal merupakan hal yang harus dituju oleh tiap perusahaan.Hal ini akan dapat menjadi "penolong" bagi perusahaan ketika produk yang ditawarkan perusahaan bukan merupakan produk yang terbaik di pasaran. Perilaku konsumen yang "irasional" tersebut dapat tercipta ketika perusahaan mampu untuk menjaga hubungan baik dengan pelanggan. Sehingga, pelanggan tersebut memiliki intensi untuk loyal terhadap produk-produk yang ditawarkan perusahaan meskipun bukan produk terbaik yang dimiliki oleh perusahaan (Imasari \& Nurasalin,2011). Hal ini sesuai denganhasil penelitian yang dilakukan oleh (Adnin, Lubis, \& Widayanto, 2013) menemukan bahwa Customer Relationship Management 
berpengaruh positif dan signifikan terhadap niat untuk loyal pelanggan PT.Nasmoco Pemuda Semarang.Begitupun dengan hasil penelitian ini yang menemukan bahwa customer relationship management berpengaruh positif dan signifikan terhadap niat untuk loyal atau loyalty intention pada travel agent di Mataram.Hal ini memberi arti bahwa semakin baik customer relationship management yang dilakukan oleh Travel Agent di Mataram maka akan meningkatkan niat untuk loyal dari pelanggan travel agent di Mataram. Hal ini didukung oleh data empiris bahwa sekitar 47 persen wisatawan yang berkunjung ke pulau Lombok dan menggunakan travel agent di Mataram berada pada usia 36-50 tahun, hal ini menunjukan bahwa mereka merupakan generasi yang memiliki rasionaltias berpikir untuk menentukan kembali apakah akan menggunakan kembali produk-produk dari travel agent yang ditawarkan.

\subsection{Pengaruh Customer Relationship ManagementTerhadap Word of Mouth}

Hasil analisis data menunjukkan bahwa customer relationship management berpengaruh positif dan signifikan terhadapword of mouth.Sehingga hipotesis kedua yang menyatakan "customer relationship management berpengaruh positif signifikan terhadap word of mouth" diterima.Hal ini berarti jika customer relationship management dilakukan oleh perusahaan travel agent di Matarammaka akan meningkatkan intensitasword of mouth dari pelanggan tentang produk-produk dari travel agent.

Menurut Bigham (2007) komunikasi word of mouth merupakan komunikasi informal tentang produk atau jasa berbeda dengan komunikasi formal karena dalam komunikasi ini pengirim tidak berbicara dalam kapasitas seorang profesional atau komunikasi komersial.Word of mouth sendiri merupakan bentuk percakapan mengenai produk antara satu orang dengan orang lain tentang suatu pesan yang terkadang tidak disadari oleh pihak pengirim atau penerima komunikasi itu sendiri. Word of mouth membuat informasi menjadi lebih cepat untuk diterima oleh orang lain akan suatu produk dan jasa. Hal ini sesuai dengan yang dikemukakan oleh Herr (1991) dalam Bigham (2007) bahwa word of mouth memiliki tingkat impact yang lebih besar dibandingkan dengan informasi tertulis.Wangenheim (2005) menyatakan bahwa Word Of Mouth(WOM) dapat mempengaruhi perilaku, preferensi dan keinginan serta keputusan untuk membeli. Dalam Word Of Mouth(WOM), konsumenlah yang memutuskan tentang sesuatu yang sangat berharga untuk dibicarakan. Konsumen yang memiliki pengalaman unik tentang produk, jasa, dan merek dari perusahaan tertentu cenderung akan membicarakannya kepada orang lain (Hasan, 2010).

Perkembangan dunia pemasaran yang semakin kompleks dan persaingan yang semakin ketat menuntut perusahaan untuk tidak hanya berorientasi pada mencari pelanggan baru ataupun hanya menjual produk yang ada di perusahaan.Perusahaan pada saat ini dituntut untuk mampu mempertahankan dan meningkatkan kesetiaan pelanggan lama.Hal ini dapat diraih melalui pendekatan pemasara berbasis pelanggan atau customer relationship management. Meningkatkan kesetiaan pelanggan lama menjadi sangat penting karena biaya untuk memperoleh pembeli yang baru dapat lima kali lebih mahal dibandingkan dengan biaya yang digunakan untuk mempertahankan pelanggan yang lama (Sutrisno,2015). Menjalin hubungan dengan pelanggan atau customer relationship management merupakan salah satu upaya untuk menumbukan basis pelanggan agar memiliki intensi untuk loyal kepada perusahaan.Penjelasan yang mendasari terbentuknya pengaruh manajemen hubunganpelanggan (customer 
relationship management) mengacu dari teori diskonfirmasiharapan (expectancydisconfirmation theory) yang menjelaskan bahwa pelangganmembeli barang dan jasa dengan harapan pada saat pra-pembelian dilakukanpenilaian kinerja dari barang maupun jasa yang telah dibeli oleh pelanggan.Setelahproduk atau jasa yang telah dibeli dan digunakan, hasilnya dapat dibandingkandengan harapan (ekspektasi) pelanggan, jika hasilnya sesuai harapan pelangganberarti telah terjadi konfirmasi. Sedangkan diskonfirmasi terjadi ketika adaperbedaan antara harapan dan hasil (Dimyati,2016).

Hasil penelitian ini menemukan bahwa customer relationship management memiliki pengaruh yang positif dan signifikan terhadap word of mouth. Hal ini menunjukkan bahwa customer relationship management yang dilakukan oleh travel agent di Mataram akan meningkatkan word of mouth pelanggan yang menggunakan travel agent di Mataram atau dengan kata lain, pelanggan akan menceritakan kembali kepada kerabat tentang travel agent di Mataram setelah merasakan atau menggunakannya. Penelitian ini sesuai dengan penelitian yang dilakukan oleh oleh (Yuristika, Faridia, \& Dewi, 2015) yang menemukan customer relationship management berpengaruh terhadap word of mouth.Hal ini didukung oleh data empiris yang menemukan bahwa 48 persen responden memiliki waktu masa kunjungan di Pulau Lombok selama 3 hingga 4 hari.Hal ini menunjukkan bahwa selama masa kunjungan pelanggan tersebut, tentu pelanggan berada pada tanggung jawab travel agent di Mataram sehingga, pelanggan memilik waktu yang cukup untuk merasakan pelayanan dari travel agent dan dapat memberikan rekomendasi kepada kerabatnya. Sehingga, semakin baik customer relationship management yang dilakukan oleh travel agent di Mataram maka akan meningkatkan intensitas pelanggan dalam menceritakan layanan travel agent di Mataram.

\subsection{Pengaruh Word of Mouth Terhadap Loyalty Intention}

Hasil analisis data menunjukkan bahwa word of mouth berpengaruh positif dan signifikan terhadaployalty intention.Sehingga hipotesis ketiga yang menyatakan "word of mouth berpengaruh positif signifikan terhadap loyalty intention" di terima.Hal ini berarti ketika pelanggan travel agent di Mataram merekomendasikan kepada kerabatnya akan meningkatkan loyalty intention atau niat untuk loyal dari pelanggan tersebut pada travel agent di Mataram.

Word of mouth merupakan suatu bentuk promosi yang berupa rekomendasi dan tersebar dari mulut ke mulut tentang kelebihan suatu produk (Lupiyoadi, 2006). WOM terjadi ketika konsumen berbicara mengenai pendapatnya tentang produk atau jasa kepada orang lain. Setelah merasakan produk dan layanan dari travel agent maka pelanggan akan menceritakan dan merekomendasikan produk dari travel agent tersebut. MenurutMc.Dougall dan Levesque (2001), dimana niat untuk loyal bukan merupakan loyalitas tentang kesikapan maupun loyalitas keperilakuan, tetapi niat untuk loyal tersebut didefinisikan sebagai kemungkinan yang subjektif bahwa seorang konsumen akan berperilaku loyal (melakukan pembelian ulang, merekomendasikan kepada orang lain, atau melakukan positif word of mouth setelah merasakan manfaat dari suatu produk atau jasa yang sudah dikonsumsi).

Berdasarkan dari data deskriptif penelitian pada variabelword of mouth yang ada, rata-rata kategori variabel word of mouth berada pada kategori cukup intens. Hal ini mengindikasikan bahwa intensitas pelanggan untuk memberikan rekomendasi kepada 
kerabatnya di tempat lain dan menjadikannya untuk loyal sudah cukup maksimal. Hal ini dibuktikan dengan nilai rata-rata kategori hanya masuk pada cukup intens sehingga membuat pelanggan lain atau kerabat yang diinformasikan atau diceritakan memiliki niat untuk loyal pada travel agent di Mataram. Hasil penelitian ini sesuai dengan hasil penelitian yang dilakukan oleh Yunita dan Haryanto (2012) yang menemukan bahwa word of mouth akan membuat pelanggan untuk loyal, paling tidak pelanggan mengetahui produk yang digunakan dan ketika diceritakan produk tersebut baik maka niat untuk loyal pasti akan meningkat.

\subsection{Pengaruh Customer Relationship Management Terhadap Loyalty Intentiondengan MediasiWord of Mouth}

Berdasarkan hasil yang ditunjukkan, penelitian ini menyatakan bahwa loyalty intention dipengaruhi oleh customer relationship management dengan mediasi word of mouth.Hal ini ditunjukkan dengan variabel customer relationship management dengan mediasi word of mouthdapat mempengaruhi loyalty intentionpelanggan travel agent di Mataramdengan nilai koefisien jalur sebesar 0,086.Dari perhitungan tersebut, memberi arti bahwa terdapat pengaruh tidak langsung antara variabel customer relationship management dengan loyalty intention melalui word of mouth dengan nilai koefisien jalur sebesar 0,086.Perbandingan pengaruh tidak langsung customer relationship managementdengan loyalty intentionmelalui word of mouthdengan pengaruh langsungnya antara customer relationship managementterhadap loyalty intentiondiperoleh hasil 0,086< 0,371 sehingga bisa dinyatakan bahwa word of mouth berfungsi sebagai mediasi parsial (partial mediation) dalam pengaruh customer relationship managementterhadap loyalty intentionpada pelanggan travel agent di Mataram. Artinya customer relationship management mampu mempengaruhi secara langsung loyalty intentionbaik melaluiword of mouth maupun tanpa melalui word of mouth.

Temuan ini memberikan pedoman bagi perusahaan travel agent di Mataram untuk meningkatkan kualitas dari customer relationship management-nya agar mampu memberikan dampak positif kepada kepada word of mouth dan mampu membuat calon pelanggan yang direkomendasikan langsung memiliki niat untuk loyal kepada perusahaan. Pengaruh antara customer relationship management terhadap word ofmouth positif dan signifikan, hal ini menunjukkan bahwa hubungan pelanggan yang baik akan meningkatkan word of mouth dari pelanggan travel agent di Mataram atau dengan kata lain, apabila pelanggan merasa travel agent telah memiliki hubungan pelanggan yang baik maka mereka akan merekomendasikan hal tersebut kepada kerabatnya dan word of mouth memiliki pengaruh yang positif dan signifikan terhadap loyalty intention. Hal ini menunjukkan bahwa meskipun pelanggan tersebut menceritakan atau bahkan merekomendasikan produk dan layanan dari travel agent maka akan membuat orang yang diceritakan langsung memiliki niat untuk loyal pada travel agent di Mataram. Menurut Parasuraman et.al dalam Akbar dan parvez (2009:27), loyalitas konsumen tidak muncul begitu saja pada seseorang, tetapi tercipta melalui beberapa tahap yang diawali dengan munculnya suatu keinginan atau niat untuk loyal (loyalty intention). Hal ini mengindikasikan bahwa niat seseorang untuk loyal dapat muncul ketika mendegar atau diceritakan oleh kerabat yang pernah merasakan produk dan jasa dari perusahaan.Hal ini diperkuat oleh Oliver dalam Sutrisno (2016) yang menyatakan bahwa niat untuk loyal adalah komitmen bertahan yang mendalam dari 
konsumen untuk berlanggan kembali atau melakukan pembelian ulang produk atau jasa terpilih secara konsisten di masa kan datang meskipun situasi dan kondisi iklm perdagangan senantiasa berpotensi untuk menyebabkan perubahan perilaku dari konsumen. Artinya, konsumen telah atau pernah terlebih dahulu merasakan layanan produk dan jasa dari perusahaan sehingga baru akan menimbulkan niat untk loyal terhadap perusahaan. Word of Mouth terjadi ketika konsumen berbicara mengenai pendapatnya tentang produk atau jasa kepada orang lain. Hasil penelitian ini sesuai dengan penelitian yang dilakukan oleh Riduan (2010)yang menemukan WOM akan berpengaruh atau akan meningkatkan niat loyalitas dari pelanggan pada jasa Travel Muara Wisata.

\section{Kesimpulan}

Berdasarkan hasil penelitian pada responden 100responden yang menggunakan travel agent di Mataram mengenai pengaruh customer relationship managementterhadap loyalty intention dengan word of mouth sebagai mediasi, maka dapat disimpulkan beberapa hal sebagai berikut ini :

1. Customer relationship management berpengaruh positif dan signifikan terhadaployalty intention. Hal ini memberi arti bahwa semakin baik customer relationship management yang dilakukan oleh Travel Agent di Mataram maka akan meningkatkan niat untuk loyal dari pelanggan travel agent di Mataram.

2. Customer relationship management berpengaruh positif dan signifikan terhadapword of mouth. Hal ini menunjukkan bahwa customer relationship management yang dilakukan oleh travel agent di Mataram akan meningkatkan word of mouth pelanggan yang menggunakan travel agent di Mataram atau dengan kata lain, pelanggan akan menceritakan kembali kepada kerabat tentang travel agent di Mataram setelah merasakan atau menggunakannya

3. Word of mouth berpengaruh positif dansignifikan terhadap loyalty intention. Hal ini memberikan gambaran bahwa semakin intens pelanggan yang menggunakan travel agent di Mataram menceritakan pengalamannya maka akan meningkatkan loyalty intention terhadap travel agent di Mataram

4. Customer Relationship managementberpengaruh positif dansignifikan terhadap loyalty intention yang dimediasi olehword of mouth secara parsial. Hal ini menunjukkan bahwabaik adanya word of mouth maupun tidak ada word of mouth akan tetap mampu mempengaruhiloyalty intention dari pelanggan travel agent di Mataram.

Hasil penelitian ini menjadi tambahan bukti empiris bagi teori atau konsep yang melandasi hubungan yang telah digambarkan dalam model penelitian ini. Penelitian ini dapat membuktikan bahwa terdapat pengaruh langsung dari Customer Relationship Management dan word of Mouth terhadap Loyalty Intention pelanggan travel agent di Matarm. Pengaruh langsung dari customer relationship management terhadap loyalty intention pada pelanggan di travel agent mataram dan penelitian ini memberikan bukti bahwa word of mouth menjadi partial mediation hubungan antara customer relationship management terhadap loyalty intention pada pelanggan di trave agent di Mataram. 
Berdasarkan pembahasan dan simpulan yang telah dikemkakan sebelumnya, maka terdapat implikasi manajerial dari penelitian ini adalah :

1. Untuk Customer Relationship Management, travel agent di Mataram diharapkan mampu meningkatkan pelayanan terutama pada saat pelanggan akan menyampaikan keluhannya agar keluhan tersebut dapat di pahami dan di respon dengan cepat. Travel agent dapat membuat kotak saran di kantor-kantor travel agent atau dapat membuat layanan aduan keluhan melalui website travel agent.

2. Agar pelanggan merekomendasikan perusahaan atau travel agent di Mataram, maka travel agent harus meningkatkan kualitas layanan baik dari segi produk-produk yang ditawarkan agar lebih variatif dan meningkatkan layanan pada saat pelanggan menghadapi permasalahan.

3. Meningkatkan layanan travel agent agar pelanggan puas dan ingin kembali menggunakan produk dan jasa dari travel agent di Mataram

\section{Daftar Pustaka}

Adnin, Rizqa Janati, Nawazirul Lubis dan Widayanto. 2013. Pengaruh Customer Relationship Management terhadap Loyalitas Pelanggan PT Nasmoco Pemuda Semarang, Jurnal Sosial dan Politik Vol. 2 No. 6. Hal. 1-8.

Akbar M.M and Parvez. 2009. Impact of Service Quality, Trust, and Customer Satisfaction Loyalty, ABAC Journal, Vol. 29, No.1.Januari, 24-38.

Alma, B.2010. Kewirausahaan Untuk Mahasiswa dan Umum.Bandung:Alfabeta

Bigham, A. 2007. Word of Mouth Research: Principles and Applications. Journal of Advertising Research, pp:394-420

Davis, M.2002 The Effect of Customer Relationship Management on Loyalty. Journal of Managemet, pp 145-189

Doong, H,S, Wang, H,C dan Shih, C,H. 2008. "Exploring Loyalty Intention in The Electronic Marketplace. Journal of electronic marketing, pp: 142-149

Ajzen,I.,\&Fishbein,M.(1980).Understanding attitudes and predicting social behavior. Englewood Cliffs, NJ: Prenti

Fishbein dan Ajzen (1975).Understanding Attitudes and Predicting Social Behaviour. Engelwood Cliffs, NJ: Prentice Hall

Gremler and Brown. 1997. Customer Relationship Marketing: A Strategic Imperative in the World of e.Business. John Wiley and Sons Ltd. Canada.

Hasan, Ali. 2010. "Marketing" Jogjakarta : Media Presindo

McDougall, G.H.G. and Levesque, T. (2001), "Customer Satisfaction With Services: Putting Perceived Value Into The Equation", Journal of Services Marketing, Vol. 14 No. 5, pp. 392-41.

Neupane, Ramesh. 2015. The Effects of Brand Image on Customer Satisfaction and Loyalty Intention in Retail Supermarket Chain UK. Journal Social Science Manage. Vol. 2, No.1, Hal. 9-26

Oktariana, Fauzi A \& Kumadji. 2017. Faktor-faktor Customer Relationship Management Dalam Mewujudkan Kepuasan Anggota dan Dampaknya Terhadap Loyalitas Anggota. Jurnal Profit, Vol.6 No.2, 149-162

Riduan. 2010. "Pengaruh Word of Mouth Communication Terhadap Loyalitas Pelanggan Padajasa Travel Muara Wisata Trayek Lampung-Jakarta" Jurnal Bisnis Indonesia Vol. 1. No.. pp: $45-55$ 
Semuel, H.2012. Customer Customer Relationship Management Pengaruhnya Terhadap Kepercayaan dan Loyalitas Perbankan Nasional.Jurnal Manajemen Pemasaran, Vol.7, No.1, pp; 33-41

Silverman,J.2001.Promotion on its Function to MCustomer Relationship Management and Word of Mouth. Journal of Strategic Management, pp: 41-67

Solomon, M. R. (2007). "Consumer Behavior: Buying, Having, and Being". New Jersey, Upper Saddle River: Pearson Education, Inc.

Sutrisno. 2016. "Pengaruh Kualitas Layanan, dan Customer Rlationship Management Terhadap Kepuasan Pasien dan Loyalitas Pasien di Rumah Sakit Tingkat II TNI.Jurnal Ilmu Ekonomi dan Manajemen, Vol.2 No.2, pp: 27-41

Swastha B. 1999. Manajemen Pemasaran. Yogyakarta: Liberty Offset

Swastha B dan Handoko. 2011. "Manajemen Pemasaran Modern."Yogyakarta: Liberty Offset

Trusov, P, Bucklin dan Puwels. 2008. The Impact of Customer Relationship Management On Word of Mouth. Vol.7. No.2, pp-345-388

Wangenheim, Florian v. (2005)."Postswitching Negative Word Of Mouth". Journal of Service Research, 67-78.

Yunita, A dan Haryanto J,O. "Pengaruh Word of Mouth, Iklan dan Atribut Produk Terhadap Keputusan Pembeliandan Loyalitas Konsumen" Jurnal Manajemen Teknologi, pp: 7595

Yuristika M, Faridia \& Dewi R S.2015. Pengaruh Customer Relationship Management dan Kualitas Layanan Terhadap Pembelian Ulang Melalui Word of Mouth Sebagai Variabel Mediasi. Jurnal Administrasi Bisnis, pp 1-7

Https:/ Kicknews.Today/2016/12/02/Wah-Tingkat-Kunjungan-Wisatawan-NtbSudah-tinggi-Ternyata/ Diakses Tanggal 8 Mei 2017. 